\title{
Optimalisasi Peran Guru PAUD dalam Pemantauan Tumbuh Kembang Balita dan Anak Prasekolah
}

\author{
Dian Febrida Sari ${ }^{1}$, Gina Muthia ${ }^{2}$, Putri Nelly Syofiah ${ }^{2}$ \\ ${ }^{1}$ Prodi DIII Kebidanan, STIKes MERCUBAKTIJAYA Padang \\ ${ }^{2}$ Prodi Kebidanan Program Sarjana dan Program Pendidikan Profesi Bidan, STIKes \\ MERCUBAKTIJAYA Padang \\ Jl. Jamal Jamil Pondok Kopi Siteba Padang
}

E-mail: dianfebridasari@mercubaktijaya.ac.id

\begin{abstract}
Abstrak - Pelaksanaan Program SDIDTK di Kota Padang terlaksana di seluruh Puskesmas. Pelaksanaan SDIDTK sejak bulan Januari-Juni 2018 di Puskesmas Nanggalo mencapai 61,34\% pada bayi, pada balita mencapai 88,14\%, sedangkan pada anak prasekolah hanya $28,64 \%$. Untuk pelaksanaan program SDIDTK ini dilaksanakan oleh tenaga kesehatan seperti dokter, bidan dan perawat, namun masih ada tenaga yang bisa dilibatkan salah satunya adalah guru PAUD/TK. Pada kenyataannya, guru PAUD/TK belum terpapar lebih jauh tentang pelaksanaan program ini. Oleh karena itu, penting rasanya untuk memberikan pengetahuan dan keterampilan kepada guru PAUD tentang pelaksanaan SDIDTK ini. Hal ini dilakukan karena beberapa aspek yang dinilaipada balita dan anak prasekolah dapat diamati langsung oleh guru. Guru berinteraksi dengan anak setiap hari. Harapannya adalah hasil temuan pertumbuhan dan perkembangan dari guru dapat diinformasikan kepada petugas puskesmas setiap bulannya. Solusi yang ditawarkan pada kegiatan ini adalah pelatihan tentang pelaksanaan program SDIDTK pada guru PAUD. Langkah-langkah yang dilakukan adalah identifikasi tingkat pengetahuan guru PAUD tentang Program SDIDTK dilanjutkan dengan pemberian materi tentang SDIDTK dan bekerjasama dengan petugas puskesmas dalam mengevaluasi pelaksanaan program. Luaran berupa publikasi artikel di Jurnal Pengabdian Msyarakat yang ber ISSN, Sosial Media dan peningkatan pemberdayaan masyarakat dan penguatan pengetahuan dan pengembangan kebiasaan masyarakat dalam berprilaku sehat.
\end{abstract}

Kata Kunci — Tumbuh Kembang, Balita, PAUD, Anak prasekolah

\begin{abstract}
The implementation of the SDIDnTK Program in Padang City was carried out in all Puskesmas Kota Padang. SDIDTK implementation since January-Jue 2018 in Nanggalo Public Health Center has only reached 61,34\% of infants, only $88,14 \%$ toddlers, while in preschool children only $28,64 \%$. For the implementation of this program, there are still workers who can be involved, one of which is a PAUD/TK teacher. But in reality, PAUD/TK teachers have not been further exposed about the implementation of this program. Therefore it is important to provide knowledge and skills to PAUD teachers about this SDIDTK, because several aspects are assessed, can be observed directly by the teacher. The teacher interacts with ank every day. The hope is that the findings of the growth and development of teachers can be informed to the health center staff every month. The solution offered in this activity is training on the implementation of the SDIDTK program for PAUD teachers and making a communication book. The steps taken are identifying the level of PAUD teacher's knowledge of the SDIDTK Program followed by providing material about SDIDTK and working with the health center staff in evaluating the implementation of the program. Output in the form of publication of articles in the ISSN Journal of Communication Service, Social Media and improvement of community empowerment and strengthening of knowledge and development of community habits in helathy behavior.
\end{abstract}

Keywords — Growth and development, Toddler, PAUD, Preschoolers

\section{Pendahuluan}

Pelaksanaan Program SDIDTK di Kota Padang terlaksana di seluruh Puskesmas Kota Padang. Namun tidak semua Puskesmas yang mencapai target nasional yaitu 90\%, salah satunya adalah Puskesmas Nanggalo. Jumlah balita yang ditimbang per sasaran $(\mathrm{D} / \mathrm{S})$ hanya $52,04 \%(1)$.

Berdasarkan hasil wawancara dengan Penanggung Jawab program SDIDTK Puskesmas Nanggalo didapatkan data bahwa saat ini program SDIDTK ini hanya dilaksanakan oleh tenaga kesehatan dari Puskesmas seperti bidan dan perawat. Padahal dokter, bidan dan perawat masih memiliki bebarapa tugas dan tanggung jawab lainnya terkait kesehatan masyarakat. Untuk kegiatan SDIDTK ini, setiap anak akan dinilai pada waktu yang berbeda-beda sesuai umur. Hal ini yang membuat keterbatasan waktu dari tenaga kesehatan untuk melakukan SDIDTK ini.

Stimulasi Deteksi dan Intervensi Dini Tumbuh Kembang Anak (SDIDTK) merupakan salah satu program pemerintah yang bertujuan untuk 
meningkatkan kualitas tumbuh kembang anak usia dini dan kesiapan memasuki jenjang pendidikan formal. SDIDTK merupakan bentuk kemitraan antara keluarga (orang tua, pengasuh anak dan anggota keluarga lain), masyarakat (kader, tokoh masyarakat, organisasi profesi dan sebagainya) dan tenaga profesional (kesehatan, pendidikan dan sosial) yang difasilitasi oleh Dinas Kesehatan melalui Puskesmas dalam Program Posyandu (PAUD, Bina Keluarga Balita (BKB), Panti Sosial Anak, Puskesmas, Pustu, Polindes dan Poskesdes) (2).

Untuk pelaksanaan program SDIDTK, masih ada tenaga yang bisa dilibatkan salah satunya adalah guru PAUD/TK (2). Namun kenyataannya, guru PAUD/TK belum terpapar lebih jauh tentang pelaksanaan program ini. Oleh karena itu sangat penting memberikan pengetahuan dan keterampilan kepada guru PAUD tentang program SDIDTK ini (3).

\section{SOLUSI PERMASALAHAN}

Solusi yang ditawarkan untuk menyelesaikan masalah adalah sosialisasi dan pelatihan tentang pelaksanaan program SDIDTK pada guru PAUD. Hal ini dilakukan agar guru PAUD dan TK mendapatkan pengetahuan tentang program SDIDTK. Hal ini mengacu kepada hasil abdimas Indrayani dan Novriana (2018) yaitu terdapat peningkatan pengetahuan guru PAUD/TK tentang teknik deteksi dini tumbuh kembang anak dengan metode pretes, ceramah, diskusi, demonstrasi dan postes (4).

Hasil penelitian serupa juga telah dilakukan oleh Suryandari dan Purwanti (2018) yaitu terdapat hubungan antara pengetahuan guru PAUD/TK tentang SDIDTK dengan pelaksanaan deteksi penyimpangan perkembangan (P value 0.05) (5)

\section{METODE PELAKSANAAN}

Pelaksanaan program pengabdian masyarakat ini dimulai dengan koordinasi dengan TK Islam Shabrina dan PAUD Maghfirah tentang jumlah guru, jadwal, waktu dan tempat pelaksanaan kegiatan. Setelah tim menyepakati waktu pelaksanaan dengan mitra, tahapan kegiatan yang dilakukan sebagai berikut :

a. Pengabdi melakukan pretest kepada guru terkait dengan pengetahuan tentang SDIDTK

b. Pengabdi menyampaikan materi tentang Stimulasi Dini Tumbuh Kembang Anak, Deteksi Dini Tumbuh Kembang Anak dan Intervensi Dini Tumbuh Kembang Anak

c. Pengabdi melakukan demonstrasi tentang deteksi dini tumbuh kembang pada baliat dan anak prasekolah

d. Pengabdi melakukan posttest kepada guru PAUD/TK terkait dengan materi yang sudah disampaikan

e. Tim pengusul melibatkan peran serta mahasiswa dalam membantu kelancaran program yang akan dilaksanakan serta dapat menambah wawasan mahasiswa untuk menerapkan ilmunya secara langsung di lapangan. adalah :

Metode yang digunakan dalam kegiatan ini

a. Menguji tingkat pengetahuan guru PAUD dan TK sebelum dan sesudah penyampaian materi untuk mengetahui peningkatan pengetahuan guru tentang SDIDTK

b. Pemberian materi dengan metode ceramah yaitu tentang stimulasi, deteksi dan intervensi dini tumbuh kembang anak.

c. Demonstrasi dan redemonstrasi deteksi tumbuh kembang anak

\section{HASIL DAN PEMBAHASAN}

Target utama dari pelaksanaan kegiatan pengabdian masyarakat ini adalah guru PAUD dan TK memahami dan mengetahui program SDIDTK dan dapat melaksanakannya kepada peserta didiknya sehingga dapat mendeteksi sedini mungkin gangguan tumbuh kembang pada peserta didiknya.

Adapun hasil kegiatan pengabdian yang telah dilakukan adalah sebagai berikut :

a. Pengabdi melakukan pretest tingkat pengetahuan tentang SDIDTK kepada guru menggunakan kuesioner yang diisi sebelum kegiatan dimulai.

Tabel 1. Analisis Item Tingkat Pengetahuan guru TK tentang SDIDTK (Pretes)

\begin{tabular}{ccccc}
\hline No & (f) Benar & \% & (f) Salah & \% \\
\hline 1 & 8 & 100 & 0 & 0 \\
2 & 2 & 25 & 6 & 75 \\
3 & 8 & 100 & 0 & 0 \\
4 & 7 & 87.5 & 1 & 12.5 \\
5 & 0 & 0 & 8 & 100 \\
6 & 5 & 62.5 & 3 & 37.5 \\
7 & 6 & 75 & 2 & 25 \\
8 & 7 & 87.5 & 1 & 12.5 \\
9 & 8 & 100 & 0 & 0 \\
10 & 7 & 87.5 & 1 & 12.5 \\
11 & 5 & 62.5 & 3 & 37.5 \\
12 & 8 & 100 & 0 & 0 \\
13 & 2 & 25 & 6 & 75 \\
14 & 8 & 100 & 0 & 0 \\
15 & 4 & 50 & 4 & 50 \\
16 & 8 & 100 & 0 & 0 \\
17 & 6 & 75 & 2 & 25 \\
18 & 0 & 0 & 8 & 100 \\
19 & 7 & 87.5 & 1 & 12.5 \\
20 & 8 & 100 & 0 & 0 \\
\hline
\end{tabular}

Hasilnya sebagai berikut dari 20 pertanyaan yang diajukan terdapat 2 pertanyaan yang dijawab salah oleh semua responden yaitu pertanyaan mengenai indikator penilaian perkembangan dan konsultasi permasalahan tumbuh kembang pada balita dan anak prasekolah. Dan 1 pertanyaan dijawab salah oleh sebagian responden $(50 \%)$ yaitu tentang pengukuran LKA (Lingkar Kepala Anak). 
b. Pengabdi menyampaikan materi tentang Stimulasi Dini Tumbuh Kembang Anak, Deteksi Dini Tumbuh Kembang Anak dan Intervensi Dini Tumbuh Kembang Anak.

Kegiatan dimulai dengan sambutan dari tuan rumah yaitu Ibu Animar, S.Pbeliau menyampaikan ucapan terimakasih karena pengabdi telah memilih lokasi abdimas di TK Shabrina dan telah mengikutsertalkan semua guru dari TK Shabrina dan PAUD Maghfirah dalam kegiatan ini. Harapannya adalah agar kegiatan ini dapat dilaksanakan secara berkala agar para guru dapat melaksanakan DDTK sesuai jadwal dan dapat membantu Puskesmas dalam menjalankan salah satu program pemerintah.

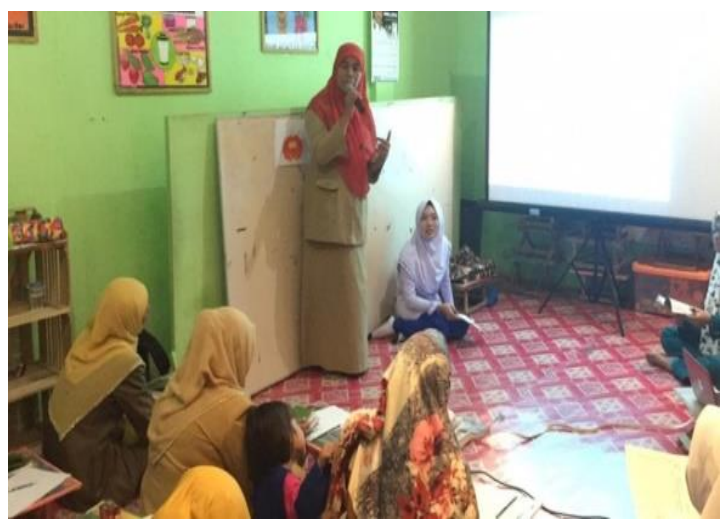

Gambar 1. Kata Sambutan dari Kepala Sekolah TK Islam Shabrina.

Kemudian dilanjutkan dengan pemberian materi oleh narasumber sebagai berikut:

Tabel 2. Materi dan narasumber kegaitan abdimas

\begin{tabular}{cll}
\hline No & \multicolumn{1}{c}{ Materi } & \multicolumn{1}{c}{ Narasumber } \\
\hline 1 & Stimulasi tumbuh kembang & Gina Muthia \\
2 & $\begin{array}{l}\text { Deteksi dan Intervensi Dini } \\
\text { tumbuh kembang }\end{array}$ & Dian Febrida Sari \\
3 & $\begin{array}{l}\text { Demonstrasi deteksi tumbuh } \\
\text { kembang }\end{array}$ & Putri Nelly Syofiah \\
\hline
\end{tabular}

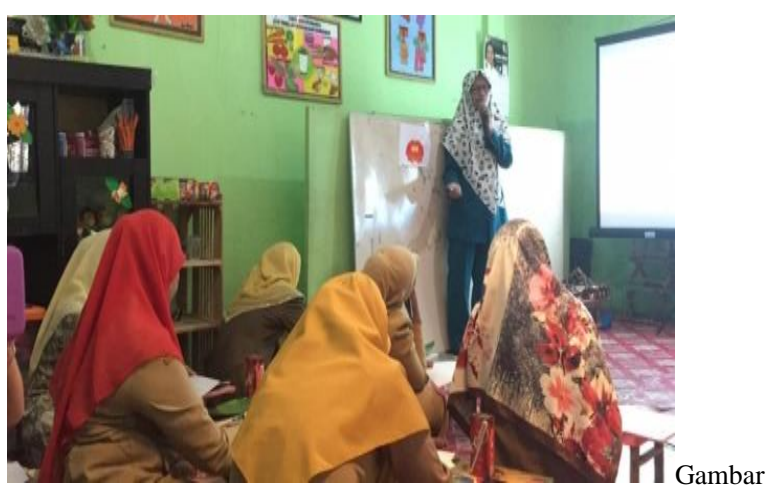

2. Pemberian materi tentang Stimulasi Tumbuh Kembang oleh Gina Muthia, S.SiT., M.Keb

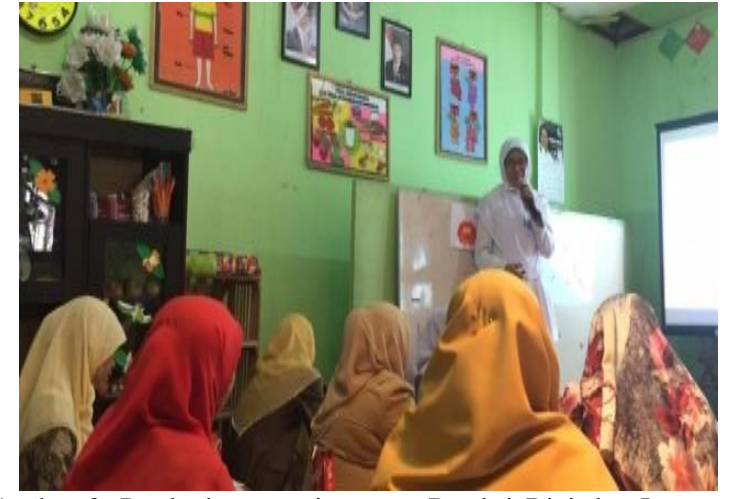

Gambar 3. Pemberian materi tentang Deteksi Dini dan Intervensi Tumbuh Kembang oleh Dian Febrida Sari, S.Si.T., M.Keb

c. Setelah dilakukan pemberian materi, agar peserta dapat melakukan kegiatan ini, maka tim pengabdi juga melakukan demonstrasi Deteksi Dini Tumbuh Kembang pada balita dan anak prasekolah

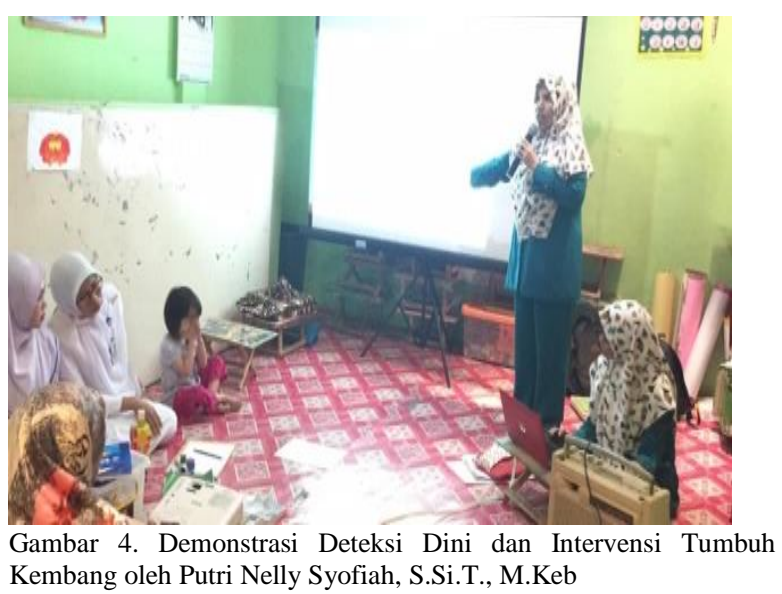

Kembang oleh Putri Nelly Syofiah, S.Si.T., M.Keb 
d. Pengabdi melakukan posttest kepada guru PAUD/TK terkait dengan materi yang sudah disampaikan.

Dari 20 pertanyaan yang diberikan, masih ada beberapa pertanyaan yang masih belum terjawab benar oleh seluruh peserta yaitu pertanyaan tentang jadwal penyegaran materi SDIDTK pada guru PAUD.

Tabel 3. Analisis Item Tingkat Pengetahuan guru TK tentang SDIDTK (Postes)

\begin{tabular}{ccccc}
\hline No & (f) Benar & \% & (f) Salah & \% \\
\hline 1 & 8 & 100 & 0 & 0 \\
2 & 6 & 75 & 2 & 25 \\
3 & 8 & 100 & 0 & 0 \\
4 & 7 & 87.5 & 1 & 12.5 \\
5 & 4 & 50 & 4 & 50 \\
6 & 5 & 62.5 & 3 & 37.5 \\
7 & 6 & 75 & 2 & 25 \\
8 & 7 & 87.5 & 1 & 12.5 \\
9 & 8 & 100 & 0 & 0 \\
10 & 7 & 87.5 & 1 & 12.5 \\
11 & 5 & 62.5 & 3 & 37.5 \\
12 & 8 & 100 & 0 & 0 \\
13 & 5 & 62.5 & 3 & 37.5 \\
14 & 8 & 100 & 0 & 0 \\
15 & 4 & 50 & 4 & 50 \\
16 & 8 & 100 & 0 & 0 \\
17 & 6 & 75 & 2 & 25 \\
18 & 8 & 100 & 0 & 0 \\
19 & 7 & 87.5 & 1 & 12.5 \\
20 & 8 & 100 & 0 & 0 \\
\hline
\end{tabular}

Berikut adalah rekapitulasi hasil penilaian pretes dan postes pada peserta kegiatan sosialisasi ini.

Tabel 4. Tingkat pengetahuan guru tentang SDIDTK sebelum dan sesudah pemberian materi

\begin{tabular}{|c|c|}
\hline Sebelum & Setelah \\
\hline $\begin{array}{l}62,5 \% \text { guru belum mengetahui } \\
\text { bahwa deteksi dini tumbuh } \\
\text { kembang hanya dapat dilakukan } \\
\text { oleh tenaga kesehatan }\end{array}$ & $\begin{array}{l}100 \% \text { guru mengetahui } \\
\text { bahwa deteksi dini tumbuh } \\
\text { kembang hanya dapat } \\
\text { dilakukan oleh tenaga } \\
\text { kesehatan }\end{array}$ \\
\hline $\begin{array}{l}75 \% \text { guru belum mengetahui } \\
\text { tentang penghitungan umur } \\
\text { balita bahwa jika umur lebih } 15 \\
\text { hari dibulatkan menjadi } 1 \\
\text { bulan. Misal } 40 \text { bulan } 15 \text { hari, } \\
\text { dibulatkan menjadi } 41 \text { bulan. }\end{array}$ & $\begin{array}{l}100 \% \text { guru mengetahui } \\
\text { tentang penghitungan umur } \\
\text { balita bahwa jika umur lebih } \\
15 \text { hari dibulatkan menjadi } 1 \\
\text { bulan. Misal } 40 \text { bulan } 15 \\
\text { hari, dibulatkan menjadi } 41 \\
\text { bulan. }\end{array}$ \\
\hline $\begin{array}{l}100 \% \text { guru belum mengetahui } \\
\text { tentang empat indikator } \\
\text { penilaian perkembangan adalah } \\
\text { gerak halus, gerak kasar, } \\
\text { kemampuan bicara dan bahasa } \\
\text { serta sosialisasi dan } \\
\text { kemandirian }\end{array}$ & $\begin{array}{l}100 \% \text { guru mengetahui } \\
\text { tentang empat indikator } \\
\text { penilaian perkembanagn } \\
\text { adalah gerak halus, gerak } \\
\text { kasar, kemampuan bicara } \\
\text { dan bahasa serta sosialisasi } \\
\text { dan kemandirian }\end{array}$ \\
\hline
\end{tabular}

\section{KESIMPULAN}

Kegiatan pengabdian kepada masyarakat dengan judul "Optimalisasi Peran Guru PAUD dalam Pemantauan Tumbuh Kembang Balita dan Anak Prasekolah" ini telah dilaksanakan pada tanggal 14 Oktober 2019 di TK Islam Shabrina. Kegiatan ini diikuti oleh 6 orang guru TK dan 2 orang kepala sekolah.

Semua peserta sangat antusias selama pelaksanaan kegiatan. Hal ini dibuktikan dengan banyaknya pertanyaan yang muncul dari peserta berdasarkan pengalaman yang telah dialami oleh guru selama mendidik siswa PAUD dan TK.

Semua peserta memiliki peningkatan pemgetahuan tentang deteksi dini utumbuh kembang balita dan semua peserta sudah dapat melakukan penilaian pertumbuhan balita seperti pengukuran berat badan dan tinggi badan. Semua peserta juga telah dapat melakukan penilaian perkembangan balita menggunakan KPSP sesuai umur.

\section{UCAPAN TERIMAKASIH}

Terimakasih disampaikan kepada Yayasan MERCUBAKTIJAYA Padang yang telah mendanai kegiatan pengabdian masyarakat ini

\section{DAFTAR PUSTAKA}

[1]. Dinas Kesehatan Kota Padang. Profil Kesehatan tahun 2018. Padang: Dinas Kesehatan Kota Padang, 2018.

[2]. Kemenkes RI. Pedoman Pelaksanaan Stimulasi, Deteksi dan Intervensi Dini Tumbuh Kembang Anak di Tingkat Pelayanan Dasar. Jakarta: Kementrian Kesehatan Republik Indonesia, 2016.

[3]. Yuliani, Istri. 2018. Pelatihan Stimulasi Deteksi Intervensi Dini Tumbuh Kembang (SDIDTK) bagi Guru dan Wali Murid PAUD pada PAUD Baitunnur Gentan Sinduharjo Ngagik Sleman., Jurnal Pengabdian Dharma Bakti, pp. 30-38.

[4]. Indrayani, Eni dan Novriana, Eka. Purwokerto. 2018. Pelatihan Deteksi Dini Tumbuh Kembang Anak dengan Menggunakan DDST kepada Guru PAUD.: Universitas Muhammadiyah Purwokerto, The 8th University Research Colloquium. pp. 221-227.

[5]. Suryandari, Arthathi Eka dan Purwanti, Sugi. 2018. Analisis Pengetahuan Guru PAUD/TK tentang SDIDTK dengan PElaksanaan Deteksi Penyimpangan Perkembanagn Balita. Bidan Prada : Jurnal Publikasi Kebidanan, pp. 11-20. 